\title{
Mortality in Acromegalic Patients: Etiology, Trends, and Risk Factors
}

\author{
Fatmah S. Alhawyan ${ }^{1}$ \\ 1. Internal Medicine Endocrinology, Armed Forces Hospital, Abha, SAU
}

Corresponding author: Fatmah S. Alhawyan, dr-alhawayan@hotmail.com

\begin{abstract}
Although acromegaly has been associated with increased mortality rates, evidence shows that the application of the recent treatment modalities has reduced the risk of death in these patients, being comparable with the general population. As a result of the changing trends regarding mortality, the aim is to review the current literature to create enough evidence about the recent trends of mortality in patients with acromegaly. Moreover, this review aims to identify the possible etiology and the related risk factors. Old studies have reported that cardiovascular complications were the major etiology for death among acromegalic patients. However, recent studies showed that malignancies-induced complications might be the leading factor, while other studies reported that cardiovascular complications are still the main culprit. Nonetheless, the recently estimated risk is similar to that in the general population. Studies reported a decrease in mortality rates among patients with acromegaly within the last decades, which is probably attributable to the recent changes in the management updates, the less frequent exposure to radiotherapy and focus on the common cardiovascular disorders associated with the disease. This review also found that exposure to radiotherapy, old age, hypopituitarism, active acromegaly, and high growth hormone (GH) levels are significant predictors of mortality in acromegalic patients. In conclusion, more effort should be made to decrease GH to favorable levels based on the recent guidelines.
\end{abstract}

Review began 03/19/2021 Review ended 03/28/2021 Published 04/02/2021

\section{Copyright 2021}

Alhawyan. This is an open access article distributed under the terms of the Creative Commons Attribution License CC-BY 4.0., which permits unrestricted use, distribution, and reproduction in any medium, provided the original author and source are credited.

Categories: Endocrinology/Diabetes/Metabolism, Internal Medicine, Epidemiology/Public Health Keywords: growth hormone, acromegaly, risk factors, mortality

\section{Introduction And Background}

Acromegaly develops as a result of high levels of growth hormone (GH) and insulin-like growth factor-I (IGF-I) leading to many chronic systemic complications. The main etiology in $98 \%$ of these events is the GHsecreting type pituitary adenoma $[1,2]$. The disease has been found to impact both genders and is commonly diagnosed within the 40-50 age range. However, evidence shows that the diagnosis of the disease might be delayed up to 5-10 years after the first signs and symptoms [3, 4]. It has been estimated that three or four cases of acromegaly per one million population develop yearly, and the incidence seems to be stable over the years [4]. On the other hand, a previous nationwide Icelandic study reported that the incidence has increased up to seven folds in the last decade as compared to the period between 1955 and 1964 [5]. Recent studies have also reported that the prevalence of acromegaly seems to be increasing [4-6]. This has been a point of debate among studies.

Many complications have been reported with acromegaly. These include metabolic, such as hyperlipidemia, hyperglycemia and insulin resistance, cardiovascular, respiratory, neoplastic osteoarthropathy and hypopituitarism complications. Other adverse events that can occur to acromegalic patients include vertebral fractures and the possible reduction in the quality of life [6-8]. Many etiologies have been reported to be involved in the mortality of these patients, with cardiovascular complications being the commonest [6]. However, more recent studies reported that other etiologies might be involved as the risk and severity of cardiovascular disorders in these patients has recently decreased [9-11]. Although the disease is still associated with increased mortality rates, evidence shows that the application of the recent treatment modalities has reduced the risk of death in these patients, being comparable with the general population [11, 12].

Management that is focused on mortality reduction is also an important indicator for the mortality trends and prevalence in patients with acromegaly. Conventional radiotherapeutic approaches have been marked as a third-line treatment modality secondary to medical and surgical approaches $[13,14]$. Recent evidence within the last two decades shows that the mortality rates of acromegaly have been normalized secondary to the novel management modalities, where radiotherapy is used less frequently $[9,14]$. As a result of the changing trends regarding mortality, in the present study, it aims to review the current literature aiming at creating enough evidence about the recent trends of mortality in patients with acromegaly. Moreover, the study aims to identify the possible etiology and the related predicting factors.

\section{Review}




\section{Mortality in patients with acromegaly}

Evidence in the literature supports the strong association between acromegaly and the risk of mortality. A previous investigation by Colao et al. [6], that collected related reports that were previously inaugurated until 2004, reported that acromegaly increased the risk of mortality in the affected patients, and $60 \%$ of the cases were attributable to cardiovascular complications, while $25 \%$ and $15 \%$ were complicated by respiratory diseases and malignancies, respectively. In recent decades, many studies have been published, investigating the effect of the new management modalities on the reported mortality rates among these patients.

\section{Etiology of mortality}

Colao et al. reported that death in patients with acromegaly mainly occurs secondary to the presence of cardiovascular complications [6]. However, evidence from more recent studies shows that the intensity and severity of these complications have been significantly reduced over time which affected the mortality rate among these patients $[9,11,12,15-17]$. For instance, previous studies have demonstrated that death in acromegalic patients was mainly attributable to the presence of underlying malignancies followed by cardiovascular complications, and the mortality rates did not significantly differ from the reported causes and rates compared to the general population $[9,11,12,17]$. This is supported by a recent review by Gadelha et al. that showed that the presence of malignancies was the most common cause of death within the last decade in acromegaly [18]. Ritvonen et al. reported that in $34 \%$ of the included patients, cardiovascular complications were the cause of death followed by the presence of malignancies in $27 \%$ of the included patients [16]. Sherlock et al. also reported that the main causes of mortality among their patients were cardiovascular, respiratory, and cerebrovascular diseases, while malignancies were not reported among any of these patients [19]. The previous Finnish study in 2016 by Ritvonen et al. reported that the etiology of mortality among patients with acromegaly has significantly changed over the last few decades [16]. The authors reported that the development of cardiovascular complications was the major etiology of mortality within the earlier decades, while complications secondary to malignancies were the major attributable causes of death within the following two decades. Esposito et al. also reported that circulatory diseases followed by malignancies were the commonest causes of death in their population of acromegaly [20]. The authors also reported that mortality secondary to infectious diseases has increased while cardiovascular diseases have increased within the female patients.

\section{Trends of mortality: what has changed in the recent decades}

Before 1995, studies showed that the risk of acromegaly-induced mortality increased by two to three folds [21-23]. In 2008, meta-analyses studies showed that these rates were remarkably reduced. One metaanalysis by Holdaway et al. [24] that extracted data from 18 studies and followed patients with acromegaly from 1965 to 2008 reported that the standardized mortality ratio (SMR) was estimated to be 1.7 [95\% Confidence interval (CI): 1.5-2.0]. Moreover, they reported that before 1984, the SMR was 2.2 (95\% CI: 1.8 2.8), which was significantly reduced to 1.3 (95\% CI: 1.1-1.6) according to studies after this period. The other meta-analysis that was conducted by Dekkers et al. included 16 studies between 1970 and 2005 and estimated the SMR to be 1.92 (95\% CI: 1.62-1.83) [25]. Besides, the authors have analyzed their data based on two-time periods similar to the previous meta-analysis and found that the SMR was significantly reduced in patients with acromegaly from 2.11 to 1.62 , before and after 1995, respectively. This is probably due to the applied management modalities for these patients before and after these periods as the authors reported that radiotherapy was the main used modality for these patients before 1995 .

After these two meta-analyses, many other studies have also been published investigating similar outcomes. Many observational studies have reported that the SMR to acromegalic patients was found to be similar to that of the general population $[6,9,11,12,17]$. This was indicated by the Italian study in 2012 by Arosio et al. [12] that reported a SMR of 1512 patients that suffered from acromegaly at 1.13 (95\% CI: 0.87-1.46). Moreover, within the investigations that showed high SMR rates, the rates were seemingly normal after adjustment of the approached management modality. Varadhan et al. reported a significantly reduced SMR from 1.6 to 1.0, when they divided patients into two groups, before and after 1994, which supports that the SMR is significantly affected by the approached management modality [26]. Esposito et al. also estimated a high SMR of 2.79 (95\% CI: 2.43-3.15), which was significantly reduced to 0.98 and 0.45 when they analyzed patients that were treated with surgery and medical therapy combined or with surgery alone, respectively [20]. The same findings were also reported in a multinational study that compared two Italian and Bulgarian populations and found that the estimated SMR for the two cohorts were significantly different based on the approached management modalities for the included patients [15].

\section{Associated factors}

Many previous investigations have discussed the ability of certain factors to predict the death in patients with acromegaly. McCabe et al. indicated that having a history of radiotherapy exposure and old age were the most commonly reported predicting factors for mortality in these patients [27]. Bogazzi et al. also reported that radiotherapy was a significant factor in predicting mortality with an estimated hazard ratio of 34.25 [17]. The reported increased risk of mortality in these patients secondary to radiotherapy management is probably due to the development of cerebrovascular disorders [15]. It is worth mentioning that the effect of novel radiotherapeutic modalities, including the fractionated stereotactic radiotherapy and stereotactic 
radiosurgery on mortality rates in acromegalic patients is scarce and could not be evaluated in this study. In addition to radiotherapy and old age, previous studies have also demonstrated that the risk of mortality significantly increases if the disease was associated with hypopituitarism [19, 26, 27]. For instance, Sherlock et al. previously reported that the SMR for their acromegalic population significantly increased to 2.1 (95\% CI: 1.6-2.7), and 2.5 (95\% CI: 1.9-3.2) after they have noticed significant differences in the gonadotropin and ACTH hormonal levels, respectively [19]. Notably, the authors reported that only ACTH was associated with the increased risk of mortality in these patients after adjustment of several variables such as sex, age, and radiotherapy with an estimated risk ratio (RR) of 1.7 (95\% CI: 1.2-2.5). The dosage system of hydrocortisone replacement therapy had also a significant role in predicting mortality in patients with acromegaly. Sherlock et al. reported that a daily dose of 25-30 mg was associated with a RR of 1.6 (95\% CI: 1.1-2.4), which was significantly increased up to 2.9 (95\% CI: 1.4-5.9) in patients that received doses over $30 \mathrm{mg}$ per day [19]. Previous studies have also demonstrated the presence of active acromegaly is a significant indicator for death [12, 24-27]. Although Arosio et al. recently reported that the SMR for patients with acromegaly has recently normalized after the new treatment modalities, they reported that the analysis of patients that suffered from active acromegaly only showed that the SMR was significantly increased to 1.93 (95\% CI: 1.34-2.70) [12]. Therefore, creative approaches should be sought to appropriately apply disease control strategies to reduce the mortality in acromegalic patients.

\section{Acromegaly disease control}

The appropriate control of acromegaly disease has also changed over decades. McCabe et al. indicated that maintaining favorable GH levels is significantly associated with a reduced risk of mortality in patients with acromegaly [27]. The previous meta-analysis by Holdaway et al. reported that the estimated SMR for acromegalic patients was associated with the estimated levels of GH in the collected studies [24]. They reported that the SMR was significantly reduced from 1.9 (95\% CI: 1.5-2.4) to 1.1 (95\% CI: 0.9-1.4) following a reduction in GH levels from $>2.5 \mu \mathrm{g} / \mathrm{L}$ to $<2.5 \mu \mathrm{g} / \mathrm{L}$, respectively. Notably, the authors reported that the included studies have used the radioimmunoassay for measurement of the GH levels in their patients, and using modern assays to measure the GH levels indicated that the lower levels are associated with reduced risk of mortality. This is consistent with the recent investigations which reported that improved clinical outcomes were significantly associated with reduced GH levels to $<1.0 \mu \mathrm{g} / \mathrm{L}[12,15,17,24,26-29]$. Therefore, it has recently been recommended by the Endocrine Society that clinicians should target a GH level less than $1.0 \mu \mathrm{g} / \mathrm{L}$ to achieve better prognostic outcomes in patients with acromegaly [13]. On the other hand, McCabe et al. reported that such guidelines might not necessarily reflect the cumulative assessment of GH levels and their effects on the clinical outcomes [27]. The cumulative effect was investigated by Sherlock et al. [30] in a time-dependent approach and was found to be a better approach for the assessment of the prognostic outcomes as the authors reported that GH levels $<1.0 \mu \mathrm{g} / \mathrm{L}$ were associated with a RR of 1.8 for mortality, while a GH levels $<0.5 \mu \mathrm{g} / \mathrm{L}$ were associated with a lower RR of $1.5 \mathrm{among}$ the investigated patients with acromegaly by using the time-dependent approach for assessment of GH levels. Therefore, this approach should be recommended to obtain better prognostic outcomes and reduce the risk of mortality among these patients [30]. Moreover, IGF-I levels in predicting the clinical outcomes in acromegalic patients has been poorly reported in the literature [27]. The association between IGF-I and mortality in patients with acromegaly has been reported to be significant in some studies $[9,12,17]$ and insignificant in others $[15,16$, $19,26,28,30]$. Holdaway et al. estimated that the SMR was significantly higher in patients with elevated IGF-I (SMR: 2.5; 95\% CI: 1.6-4.0) than patients with normalized levels of IGF-I (SMR: 1.1; 95\% CI: 0.9-1.4) [24]. However, they also reported that only the GH level was found to be the only significant factor to predict mortality in patients with acromegaly, according to the results of the multivariate analysis.

\section{Conclusions}

The present study focused on the recent literature that investigated mortality among patients with acromegaly and the associated risk factors. We have noticed that studies have agreed that mortality rates have been reduced among patients with acromegaly within the last decades, which is probably attributable to the recent changes in the management modalities as the less frequent exposure to radiotherapy and the more frequent management of cardiovascular disorders, which has been marked as the most common cause of mortality in these patients.

\section{Additional Information \\ Disclosures}

Conflicts of interest: In compliance with the ICMJE uniform disclosure form, all authors declare the following: Payment/services info: All authors have declared that no financial support was received from any organization for the submitted work. Financial relationships: All authors have declared that they have no financial relationships at present or within the previous three years with any organizations that might have an interest in the submitted work. Other relationships: All authors have declared that there are no other relationships or activities that could appear to have influenced the submitted work.

\section{References}

1. Ben-Shlomo A, Melmed S: Acromegaly. Endocrinol Metab Clin North Am. 2008, 37:101-122. 
10.1016/j.ecl.2007.10.002

2. Colao A, Grasso LFS, Giustina A, Melmed S, Chanson P, Pereira AM, Pivonello R: Acromegaly. Nat Rev Dis Primers. 2019, 5:20. 10.1038/s41572-019-0071-6

3. Reid TJ, Post KD, Bruce JN, Nabi Kanibir M, Reyes-Vidal CM, Freda PU: Features at diagnosis of 324 patients with acromegaly did not change from 1981 to 2006: acromegaly remains under-recognized and underdiagnosed. Clin Endocrinol (Oxf). 2010, 72:203-208. 10.1111/j.1365-2265.2009.03626.x

4. Dal J, Feldt-Rasmussen U, Andersen M, et al.: Acromegaly incidence, prevalence, complications and longterm prognosis: a nationwide cohort study. Eur J Endocrinol. 2016, 175:181-190. 10.1530/eje-16-0117

5. Hoskuldsdottir GT, Fjalldal SB, Sigurjonsdottir HA: The incidence and prevalence of acromegaly, a nationwide study from 1955 through 2013. Pituitary. 2015, 18:803-807. 10.1007/s11102-015-0655-4

6. Colao A, Ferone D, Marzullo P, Lombardi G: Systemic complications of acromegaly: epidemiology, pathogenesis, and management. Endocr Rev. 2004, 25:102-152. 10.1210/er.2002-0022

7. Pivonello R, Auriemma RS, Grasso LF, et al.: Complications of acromegaly: cardiovascular, respiratory and metabolic comorbidities. Pituitary. 2017, 20:46-62. 10.1007/s11102-017-0797-7

8. Mazziotti G, Maffezzoni F, Frara S, Giustina A: Acromegalic osteopathy. Pituitary. 2017, 20:63-69. 10.1007/s11102-016-0758-6

9. Mercado M, Gonzalez B, Vargas G, et al.: Successful mortality reduction and control of comorbidities in patients with acromegaly followed at a highly specialized multidisciplinary clinic. J Clin Endocrinol Metab. 2014, 99:4438-4446. 10.1210/jc.2014-2670

10. dos Santos Silva CM, Gottlieb I, Volschan I, et al.: Low frequency of cardiomyopathy using cardiac magnetic resonance imaging in an acromegaly contemporary cohort. J Clin Endocrinol Metab. 2015, 100:4447-4455. 10.1210/jc.2015-2675

11. Maione L, Brue T, Beckers A, et al.: Changes in the management and comorbidities of acromegaly over three decades: the French Acromegaly Registry. Eur J Endocrinol. 2017, 176:645-655. 10.1530/eje-16-1064

12. Arosio M, Reimondo G, Malchiodi E, et al.: Predictors of morbidity and mortality in acromegaly: an Italian survey. Eur J Endocrinol. 2012, 167:189-198. 10.1530/eje-12-0084

13. Katznelson L, Laws ER Jr, Melmed S, Molitch ME, Murad MH, Utz A, Wass JA: Acromegaly: an endocrine society clinical practice guideline. J Clin Endocrinol Metab. 2014, 99:3933-3951. 10.1210/jc.2014-2700

14. Franzin A, Spatola G, Losa M, Picozzi P, Mortini P: Results of gamma knife radiosurgery in acromegaly . Int J Endocrinol. 2012, 2012:342034. 10.1155/2012/342034

15. Colao A, Vandeva S, Pivonello R, et al.: Could different treatment approaches in acromegaly influence life expectancy? A comparative study between Bulgaria and Campania (Italy). Eur J Endocrinol. 2014, 171:263273. 10.1530/eje-13-1022

16. Ritvonen E, Löyttyniemi E, Jaatinen P, et al.: Mortality in acromegaly: a 20-year follow-up study . Endocr Relat Cancer. 2016, 23:469-480. 10.1530/erc-16-0106

17. Bogazzi F, Colao A, Rossi G, et al.: Comparison of the effects of primary somatostatin analogue therapy and pituitary adenomectomy on survival in patients with acromegaly: a retrospective cohort study. Eur I Endocrinol. 2013, 169:367-376. 10.1530/eje-13-0166

18. Gadelha MR, Kasuki L, Lim DST, Fleseriu M: Systemic complications of acromegaly and the impact of the current treatment landscape: an update. Endocr Rev. 2019, 40:268-332. 10.1210/er.2018-00115

19. Sherlock M, Reulen RC, Alonso AA, et al.: ACTH deficiency, higher doses of hydrocortisone replacement, and radiotherapy are independent predictors of mortality in patients with acromegaly. J Clin Endocrinol Metab. 2009, 94:4216-4223. 10.1210/jc. 2009-1097

20. Esposito D, Ragnarsson O, Granfeldt D, Marlow T, Johannsson G, Olsson DS: Decreasing mortality and changes in treatment patterns in patients with acromegaly from a nationwide study. Eur J Endocrinol. 2018, 178:459-469. 10.1530/eje-18-0015

21. Wright AD, Hill DM, Lowy C, Fraser TR: Mortality in acromegaly. Q J Med. 1970, 39:1-16.

22. Alexander L, Appleton D, Hall R, Ross WM, Wilkinson R: Epidemiology of acromegaly in the Newcastle region. Clin Endocrinol (Oxf). 1980, 12:71-79. 10.1111/j.1365-2265.1980.tb03135.x

23. Rajasoorya C, Holdaway IM, Wrightson P, Scott DJ, Ibbertson HK: Determinants of clinical outcome and survival in acromegaly. Clin Endocrinol (Oxf). 1994, 41:95-102. 10.1111/j.1365-2265.1994.tb03789.x

24. Holdaway IM, Bolland MJ, Gamble GD: A meta-analysis of the effect of lowering serum levels of GH and IGF-I on mortality in acromegaly. Eur J Endocrinol. 2008, 159:89-95. 10.1530/eje-08-0267

25. Dekkers OM, Biermasz NR, Pereira AM, Romijn JA, Vandenbroucke JP: Mortality in acromegaly: a metaanalysis. J Clin Endocrinol Metab. 2008, 93:61-67. 10.1210/jc.2007-1191

26. Varadhan L, Reulen RC, Brown M, Clayton RN: The role of cumulative growth hormone exposure in determining mortality and morbidity in acromegaly: a single centre study. Pituitary. 2016, 19:251-261. 10.1007/s11102-015-0700-3

27. McCabe J, Ayuk J, Sherlock M: Treatment factors that influence mortality in acromegaly . Neuroendocrinology. 2016, 103:66-74. 10.1159/000375163

28. Ayuk J, Clayton RN, Holder G, Sheppard MC, Stewart PM, Bates AS: Growth hormone and pituitary radiotherapy, but not serum insulin-like growth factor-I concentrations, predict excess mortality in patients with acromegaly. J Clin Endocrinol Metab. 2004, 89:1613-1617. 10.1210/jc.2003-031584

29. Holdaway IM, Rajasoorya RC, Gamble GD: Factors influencing mortality in acromegaly . J Clin Endocrinol Metab. 2004, 89:667-674. 10.1210/jc.2003-031199

30. Sherlock M, Reulen RC, Aragon-Alonso A, et al.: A paradigm shift in the monitoring of patients with acromegaly: last available growth hormone may overestimate risk. J Clin Endocrinol Metab. 2014, 99:478485. 10.1210/jc.2013-2450 